\title{
REFLEXÃO SOBRE A PRÁTICA DOCENTE DE LINNGUAS ADICIONAIS SOB A PERSPECTIVA DA PEDAGOGIA DE MULTILETRAMENTOS
}

Renata de Souza Gomes ${ }^{1}$

Apresentação

Desde a formação do grupo de Nova Londres, muito se tem discutido sobre os multiletramentos e suas diretrizes pedagógicas. Nesse texto, almejo apresentar sob forma de diárioreflexivo (LIBERALI, 1999) a minha prática de sala de aula de ensino de língua inglesa como língua adicional sob a perspectiva dos multiletramentos em dois contextos diferentes do CEFET-RJ: no ensino técnico em mecânica integrado ao médio, no campus Itaguaí e nas aulas do curso de pósgraduação em línguas adicionais, no campus Maracanã no ano de 2017. No primeiro nível de ensino mencionado, serão observados o currículo proposto e a implementação das atividades pensadas para alunos do terceiro ano. Tais atividades almejam contemplar as noções de gênero textuais (emergentes e diversos), agência, autonomia, e o uso de novas tecnologias aplicadas ao ensino de língua inglesa (MILLER ,2012;PAIVA 2010; ROJO 2013).

Ao passo que na sala de aula da pós-graduação serão observados como professores de línguas adicionais em formação continuada compreendem e trabalham sob a perspectiva dos multiletramentos em seus diferentes contextos de trabalho e de que forma essa pedagogia contribui para suas práticas de sala de aula. Objetiva-se estudar os desafios da implementação da pedagogia de multiletramentos para ensino de línguas em contextos diversos de ensino e ressaltar a importância dessa prática em diversas instâncias de ensino.

\section{Caracterização da Escola}

Segundo o plano institucional do CEFET-RJ, a instituição que conhecemos hoje por CEFET/RJ, e que completa seu centenário em 2017, teve sua origem na Escola Normal de

\footnotetext{
${ }^{1}$ Doutora e Mestre em Interdisciplinar de Linguística Aplicada pela Universidade Federal do Rio de Janeiro (UFRJ), Pós-Graduada em Supervisão Escolar pela Universidade Gama Filho

(UGF). Instituição: Centro Federal de Educação Tecnológica Celso Suckow da Fonseca (CEFET-RJ), campi Itaguaí e Maracanã. E-mail: renata_souza_gomes@yahoo.com.br
} 
Artes e Ofícios Wenceslau Brás. Em uma homenagem póstuma ao seu primeiro diretor, Celso Suckow da Fonseca, a instituição passou a se chamar de Escola Técnica Federal Celso Suckow da Fonseca e foi vinculada ao Ministério da Educação (MEC), detentora de autonomia administrativa, patrimonial, financeira, didática e disciplinar, abrangendo a formação de níveis médio e superior, pós-graduação, mestrado e doutorado em áreas diversificadas. Atualmente, o CEFET-RJ oferece cursos tanta nas áreas técnicas, politécnicas ${ }^{2}$, e humanas. De acordo com o Plano de Desenvolvimento da Instituição, a missão do CEFET é:

\begin{abstract}
Promover a educação mediante atividades de ensino, pesquisa e extensão que propiciem, de modo reflexivo e crítico, na interação com a sociedade, a formação integral (humanística, científica e tecnológica, ética, política e social) de profissionais capazes de contribuir para o desenvolvimento cultural, tecnológico e econômico dessa mesma sociedade
\end{abstract}

O presente relato de experiência abrange dois diferentes campi e níveis de estudo. Farei uma breve descrição de ambos. As turmas observadas do curso técnico em mecânica integrado ao ensino médio estudam no campus da cidade de Itaguaí, onde leciono língua inglesa. O CEFET/RJ - Campus de Itaguaí, localizado na entrada do município, foi fundado com o objetivo de formar profissionais especializados na área portuária e industrial, através dos Curso técnicos em Portos, curso técnico em Mecânica integrado ao médio e de sua Graduações em Engenharia Mecânica e de Produção.

Os alunos do curso Técnico em Mecânica integrado ao Médio, são jovens de 14 a 18 anos. Em sua maioria, residem na cidade do Rio de Janeiro, e costumam ser provenientes de bairros da zona oeste carioca como Campo Grande, Santa Cruz, Paciência, Santíssimo, Bangu, Padre Miguel e adjacências, além das cidades do entorno de Itaguaí, como Mangaratiba e Seropédica, Muriqui e Itacuruçá. Observa-se um baixo número de matrículas provenientes da região de Itaguaí, e tal fato vem sendo objeto de estudos do departamento pedagógico do campus. Esses alunos agrupam-se em duas turmas de turnos distintos, em que, sem nenhum tipo de seleção prévia, os alunos fluentes e matriculados em cursos de línguas estudam pela manhã, e os chamados alunos iniciantes e não matriculados em nenhum tipo de curso de línguas (seja presencial ou à distância) estudam no turno vespertino.

O outro contexto de trabalho a ser aqui relatado é o curso de pós-graduação lato-senso em Ensino de Línguas Adicionais, vinculado ao Departamento de Línguas Estrangeiras Aplicadas do Ensino Superior, no campus Maracanã. Os alunos da turma a ser descrita nesse texto são docentes de língua espanhola (em sua grande maioria), português para estrangeiros, língua inglesa na rede

\footnotetext{
${ }^{2}$ Adoto a compreensão de politecnia proposta por Saviani (2003, P.138), e ressalto que é essa noção - de que não há ensino puramente técnico dissociado dos mundos sociais, identitários, discursivos e intelectuais, que possibilita o ensino de línguas adicionais através da perspectiva dos multiletramentos. Pois, é possível ensinar os discentes a lerem criticamente os discursos circulantes em todo mundo global.
} 
privada e/ou pública do município e Estado do Rio de Janeiro. De acordo com o Projeto de Curso aprovado, o objetivo do curso de especialização é:

\begin{abstract}
Conscientizar professores de línguas para o desenvolvimento de uma prática pedagógica pautada nos pressupostos teóricos da área da Linguística Aplicada com vistas à atuação docente em diferentes contextos de aprendizagem e à multiculturalidade e múltiplas identidades presentes em tais cenários educativos. Dotar o professor da reflexão teórico-prática sobre as políticas linguísticas e públicas relacionadas ao ensino de línguas adicionais no contexto brasileiro, bem como fundamentar a construção de novas posturas/ atitudes/ filosofias de trabalho com a lingua(gem) em contextos educacionais pelos professores participantes.
\end{abstract}

Portanto, esses objetivos foram observados na preparação das aulas a serem refletidas.

\title{
Fundamentação teórica
}

Seguindo a orientação dos pressupostos curriculares para a Especialização, eu lecionei para essa turma, a disciplina intitulada "Multiletramentos e a pedagogia de projetos no ensino de línguas adicionais", na qual meu objetivo não foi só estudar os conceitos de multiletramentos e de pedagogia de projetos, já compartilhados por muitos desses professores em formação continuada, mas também objetivei estudar e refletir a respeito dos conceitos de autonomia para ensino de línguas (PAIVA, 2005), agência discursiva (MILLER, 2012) e o uso das novas tecnologias aplicados ao ensino de línguas (ROJO, 2016). E foi através da reflexão desses conceitos, que houve um pensamento coletivo sobre práticas e eventos de letramento a serem trabalhados em nossas salas de aula de ensino de línguas sob a perspectiva dos multiletramentos e da pedagogia de projetos.

Sendo assim, eu gostaria de evidenciar que ao ter a oportunidade de trabalhar com esses dois níveis de ensino, há um ciclo de trabalho, no qual eu reflito sobre a minha prática enquanto professora da educação básica técnica e tecnológica ao mesmo tempo que ajudo a promover reflexão sobre as práticas dos meus colegas de profissão em formação continuada. Tal fato demonstra que a docência nunca está completamente formada e há sempre espaço para revisitações aos nossos saberes e práticas. Tal circunstancia também está ligada a natureza humana da docência, em seu sentido mais literal. Pois, como Paulo Freire nos apontava no célebre livro Pedagogia da Autonomia: "Gosto de ser gente porque, inacabado, sei que sou um ser condicionado mas, consciente do inacabamento, sei que posso ir mais além dele. " Dentro dessa perspectiva, ao longo das leituras e discussões dos textos contemplados na ementa do curso, o grupo compartilhava trocas de experiências sobre práticas e eventos de multiletramentos. 
A fim de amalgamar as reflexões advindas do trabalho com esses dois grupos, é feita uma comparação discursiva entre o texto do que seria meu diário reflexivo enquanto professora de dois níveis distintos de ensino dentro de uma mesma instituição e a análise do discurso dos registros reflexivos e auto-avaliativos dos alunos da pós-graduação e do ensino técnico em mecânica integrado ao médio.

O conceito de multiletramentos costura o viés das práticas aqui refletidas. A pedagogia dos multiletramentos está intimamente ligada ao chamado princípio da "irreversibilidade" (MATTOS, 2011, p. 34) na nossa sociedade contemporânea, onde as novas tecnologias promoveram novas formas de comunicação, de discursos, de semioses, e de suportes para diversos tipos de texto. Pois, segundo Mattos (2014, p.10), o advento das novas tecnologias mostrou aos pesquisadores, sobretudo ao grupo de pesquisadores de Nova Londres, que uma multiplicidade de novo textos e novas formas de comunicação estavam surgindo. E os letramentos, já compreendidos como um conjunto de práticas plurais passa a se chamar multiletramentos, ou ainda novos letramentos, devido a sua alta multiplicidade de textos visuais, audiovisuais, cinematográficos, fotográficos, midiáticos, produzidos e postados em diversos gêneros de redes sociais e etc.

Para Rojo $(2016$, p.17) o reconhecimento dos multiletramentos implica no reconhecimento e negociação de uma crescente variedade de linguagens e discursos usando interlínguas e/ou a língua inglesa como língua franca para a tradução e interpretação desses textos, ressaltando um exercício pleno do plurilinguismo bakhtiniano. Diante desse quadro, enquanto professora de dois segmentos de ensino aparentemente díspares um do outro, pude perceber a necessidade de constante atualização dos docentes, uma vez que novas discursos surgem a todo momento e atraem atenção e olhares dos leitores, ou melhor, dos "lautores", como Rojo batiza os leitores que na atualidade também interagem com o texto produzindo novos textos escritos ou orais em resposta aos que leram.

Através do intercâmbio de experiências, vimos que os gêneros textuais acabam se tornando datados, como o blog, por exemplo e tantos outros como vídeos produzidos pelos chamados youtubers e sites de fan fictions surgem com grande rapidez. Há ainda outros gêneros e discursos que se atualizam e se adaptam com grande velocidade como os memes (TAKAKI, 20XX), textos publicados no Twitter e no Instagram, onde há junção de fotografia, vídeo, snapchat, emoticons e texto escrito.

Essa velocidade de comunicações, de leituras diversas deve estar presente na escola, pois já faz parte do repertório do senso comum, a máxima que diz que a escola precisa se adaptar aos novos tempos para cativar os alunos e ensinar de forma mais eficaz. Pode-se também dizer que nunca o conceito de autonomia para o ensino de línguas foi tão atual. Pois, os discentes buscam aprender línguas através de inúmeros recursos tecnológicos, como aplicativos para o celular, por exemplo, e, segundo Paiva (2005, p.32) cabe ao professor, além do ensino da língua, o desenvolvimento de 
habilidades para que os alunos se tornem sujeitos do processo de aprendizagem. Adotando o entendimento teórico de Miller (2012, p.23), o entendimento dos discursos circulantes acontecerá de forma completa, quando houve compreensão sobre como as audiências reais o usam, o que fazem com o discurso.

\section{Descrição da experiência}

A partir da compreensão e reflexão de tais pressupostos, objetivei que minha prática de multiletramentos com os alunos do ensino médio os levasse a ler, reagir e agir discursivamente e pedi aos alunos da pós-graduação que desenvolvessem como trabalho final para a disciplina, planos de aula e/ou sequências didáticas que promovessem eventos e práticas de multiletramentos através da pedagogia de projetos. É importante ressaltar que muitos discentes da pós-graduação apontaram para o fato de que dependendo do contexto escolar no qual eles estão inseridos, não há espaço nem para a pedagogia de projetos, nem para o desenvolvimento de multiletramentos, uma vez que há ainda há uma gama de escolas com a base de ensino tradicional arraigadas em transmissão exclusiva de conteúdos gramaticais ou textos dissociados da realidade.

Dentre os gêneros escolhidos para o desenvolvimento dos multiletramentos com o Ensino Básico, o trabalho foi sempre realizado um ciclo de leitura e debate realizado na língua-alvo na turma da manhã, uma vez, que os alunos são fluentes em língua inglesa. Para a turma vespertina, adotei a metodologia de ensino de estratégias de leitura, a leitura propriamente dita na língua-alvo seguida de debate sobre os textos em língua portuguesa. O debate para ambas turmas é essencial, pois é através dele que colocamos em prática o conceito de agência discursiva e desenvolvemos a leitura crítica dos alunos.

Entre os gêneros escolhidos estão poemas como "America" do poeta Allen Ginsberg, "The Unknown Citzen"de W. H Auden, "The Unicorn in the Garden" textos jornalísticos sobre o cenário político brasileiro e internacional, cuja fonte é o jornal The Guardian Online, letras de música de Bob Dylan (recém laureado com o prêmio Nobel), memes, vídeos ativistas do Greenpeace, vídeos sobre civilizações misteriosas como os Rapa Nui, habitantes da llha de Páscoa, e vídeos advindos de canais pagos com transmissão via internet como o documentário Cowspiracy, e notícias sobre o mercado de trabalho, como, por exemplo, uma reportagem sobre os empregos mais estressantes na área técnica, nos EUA, em 2016.

A escolha por esses gêneros girou em torno dos temas propostos para as aulas: cenário político nacional, e internacional, políticas de imigração, preservação do meio ambiente, e cidadania. Fui surpreendida positivamente por alunos que interagem com o texto, reagem aos mesmo, produzem respostas, quando confrontados em um verdadeiro exercício de leitura de diferentes 
gêneros textuais. $O$ ensino de estratégia de leituras também se apresentou profícuo ao passo que grande parte dos alunos passaram a ler outros gêneros, além dos apresentados em sala de aula, como, por exemplo, a leitura da Bíblia, letras de música, e comandos de jogos de vídeo game.

O trabalho com os alunos do curso de Especialização também os levou a refletir sobre suas práticas e sobre novas formas e novos olhares de legitimação sobre o texto. Os alunos produziram em suas aulas experiências de interação e trocas interculturais via Skype entre alunos brasileiros e de outros países, trabalharam com vídeos de trocas interculturais, leitura e produção de HQs sobre Don Quixote de Cervantes, trabalhos com letras de música que questionam padrões de beleza impostos pela indústria, atividades com fotografias retiradas pelos próprios alunos na comunidade em que moram e assim por diante, curta metragens e assim por diante.

\section{Avaliação dos resultados}

Avalio todos esses resultados como benéficos e produtivos não só pelo seu aspecto prático e atrativo para o aluno tecnologicamente integrado, mas como também pelo aspecto teórico e de produção de pesquisa e teorias a respeitos dos multiletramentos. Quando ouvi, por exemplo, de uma das alunas do curso, que o trabalho com quadrinhos em sala de aula não é algo novo, mas que saber a teoria por trás dessa atividade faz toda diferença e impulsiona a trabalhar mais com HQ e com adaptações de textos literários para o ensino fundamental e médio, eu pude perceber o quanto todos nós professores precisamos avaliar nossas práticas e nos fortalecer teoricamente para que não sejamos somente consumidores de teorias, mas também pensadores da mesma.

\section{Considerações finais}

Desse modo, concluo meu texto com um convite à eterna reflexão sobre a prática docente, à prática da pedagogia dos novos letramentos e aos caminhos futuros e surpreendentes da docência.

\section{Referências}

CENTRO FEDERAL DE EDUCAÇÃO TECNOLÓGICA CELSO SUCKOW DA FONSECA. Projeto de Curso de Especialização. Disponível em: http://www.cefetri.br/attachments/article/2727/PAC\%20Linguas\%20adicionais vers\%C3\%A30\%20final\%20resolu\%C3 \%A7\%C3\%A3o.pdf. Acesso em: Maio de 2017.

FREIRE, Paulo. Pedagogia da Autonomia Saberes necessários à prática educativa. São Paulo: Paz e Terra, $165 \mathrm{p}$. 
LIBERALLI, Fernanda. O diário como ferramenta para a reflexão crítica. 1999. Tese (Doutorado em Lingüística Aplicada e Estudos da Linguagem) - PUC/SP.

MATTOS, Andrea Machado de Almeida. Novos Letramentos: Perspectivas atuais para o ensino de inglês como língua estrangeira. Signum: Estudis da Linguagem, v.17, p.102-129, 2014

MATTOS, Andrea Machado de Almeida. Novos letramentos, ensino de língua estrangeira e o papel da escola pública no século XXI. In: JORDÃO (org.).Letramentos e Multiletramentos no Ensino de Línguas e Literaturas. UFPR: Revista X, Dossiê Especial, vol. 1, 2011.

PAIVA, Vera Lucia Menezes (org.) Práticas de ensino e aprendizagem de inglês como foco na autonomia. São Paulo, Campinas: Pontes, 2007.

ROJO, Roxane. (org.). Escol@ conectada: os multiletramentos e as TICs. São Paulo: Parábola Editorial, 2013.

SAVIANI, Dermeval. 1989. Sobre a concep- ção de politecnia. Rio de Janeiro: EPSJV/ Fiocruz.

SAVIANI, Demerval. O CHOQUE TEÓRICO DA POLITECNIA THE THEORECTICAL SHOCK OF THE POLYTECHNIC. Trabalho, Educação e Saúde, 1(1):131-152, 2003. Debate Debate

TAKAKI, Nara. Futebol, Linguagens e Sociedade. In: MACIEL, R. F.; TAKAKI, N. H. (Org.) Letramentos em Terra de Paulo Freire. Campinas, SP: Pontes Editores, 2014. p.25-42. 